\title{
The Construction of Engineering Ability Training System under the Background of New Engineering
}

\author{
Peiyu Li, Weihui Pei \\ Shandong Jiaotong University \\ Jinan, Shandong
}

\begin{abstract}
Combining with the practice of the transformation and development of applied undergraduate course, this paper focuses on how to build a engineering practice system under the background of new engineering, and establishes the "engineering ability training" system with course (or project) as carrier. The "engineering ability training" system takes the extracurricular skill competition and the interdisciplinary elective course as the carrier. This paper also focuses on the practice training system of innovation and entrepreneurship, the extension research on evaluation system of engineering ability, hoping to promote the teaching reform of the applied undergraduate under the background of the new engineering.
\end{abstract}

Keywords-New engineering; Engineering ability training; System construction

\section{INTRODUCTION}

For the new engineering department, the notifications of the Higher Education Department of the Ministry of education on the research and practice of the new engineering department put forward the concept of "five new", namely, the new concept of engineering education, the new structure of subject specialty, the new model of talent cultivation, the new quality of education and teaching, and the new system of classification and development [1].

According to the requirements of the construction of the new engineering department, the quality viewpoint of "student center, achievement orientation and process guarantee" is set up, and the path of quality development from "quality achievement" to "quality culture" is gradually established, which is the only way to improve the quality of running a school for applied undergraduate colleges. In the background of the new engineering, the construction of "engineering ability training" system should be realized with reference to the idea of international educational engineering certification, through the construction of the quality management system and the normalization of the quality of teaching.

In order to meet the requirements of the new engineering construction, the practice education platform of "big project concept" is set up, the cooperative relationship of "cooperation and construction, joint training, mutual benefit and mutual benefit" is established, and various resources are established, and the practice education system of "engineering ability training" is constructed to further improve the students' practical ability in engineering and improve education. The quality of teaching.

\section{A SYSTEM OF ENGINEERING CAPABILITY TRAINING BASED ON CURRICULUM (OR PROJECT)}

\section{A. Curriculum experiment}

The project of curriculum experiment should be designed according to the characteristics of curriculum. Generally, there are different types of verification, comprehensiveness and design.

The verification experiment is mainly to solve the students' understanding of the knowledge point and the important work principle, and to verify the correctness of the conclusions through the experiment. The students' perceptual knowledge is trained and the students' ability to combine theory and practice is improved. It is usually done by students under group guidance rather than by teachers. Students should be allowed to accumulate experience from experimental mistakes. Through the experiment, the students not only achieve the purpose of mastering knowledge, but also learn the experimental methods and improve the future engineering ability. For the comprehensive and designed experiment, the teacher is more than the "coach", but not the "player". The key task is to guide, guide and change the student's excessively. Relying on the experiment instruction book, we can make students think independently, combine theory with practice, train students' engineering thinking and engineering ability [2]

\section{B. Curriculum design}

In fact, curriculum design is one of the most important teaching means to achieve the goal of teaching. It is an important fulcrum for training students' professional engineering ability, and is one of the key assessment points for students to meet the requirements of graduation

The goal of the curriculum design is very clear. That is to make a comprehensive use of the knowledge learned from the curriculum, to make a systematic combing, according to the curriculum design task assigned by the teacher, to combine the theory of curriculum and the method of calculation and design to formulate the project design scheme, and to complete the task of the course design.

To determine the task of curriculum design, we should take scientific research projects and engineering projects as the carrier, adhere to the road of cooperation between schools and enterprises and scientific research institutions, integrate 
high quality resources inside and outside schools to provide good hardware conditions for students' engineering practice, and actively explore the realization mode of engineering technicians participating in the guidance.

Curriculum design is generally carried out in groups. Training is not only the application of knowledge, but also the training and learning ability training program of team cooperation. The assessment points of curriculum design should be able to effectively support graduation requirements.

\section{Comprehensive training of professional competence}

The comprehensive training of professional ability is an important link to improve the students' ability of engineering. Therefore, the topic or project of the comprehensive training must come from the actual engineering, it is a real project, and it should also reflect the foresight.

The comprehensive training method is related to whether students can use their specialized knowledge to solve practical engineering problems. Therefore, how to organize and implement is related to the training of students' engineering ability.

The comprehensive training of professional ability should be guided by results, allowing students to learn and improve in trial and error. The role of the teacher is "coach", the student is a "player", and the comprehensive training of professional competence embodies the engineering education idea of achievement orientation, task driven, and reappearance of the work process.

\section{Graduation practice}

The main task of graduation practice is to go to the enterprise to participate in the production and operation of the enterprise, so as to be familiar with the industrial situation, the organizational structure of the enterprise, the operation mode, the contact with some customers and so on, do some work related to the professional, test their ability to solve the engineering problems, and better determine the position of their own career development. Suitable for work and accumulate experience at the same time.

The outside school practice base is an important guarantee for the normal implementation of the practical teaching link. It is an important talent training platform for students to improve their practical ability, improve their scientific research quality, and enhance their innovative consciousness and innovation ability [3]. Graduation practice is an important part of training talents for school enterprise cooperation. Students should accept the training and management of both school and enterprise during the practice of enterprise practice. Under the guidance of the guidance of the enterprise guidance teacher, the students are familiar with the process, the business activities of the enterprises, and the work of some enterprises. Under the guidance of the school teachers, the corresponding practice teaching is completed.

\section{E. Graduation design (paper)}

High quality graduation design (Thesis) should establish the operation mechanism of topic selection, division guidance, process monitoring and quality assurance. The main monitoring points include topic selection review, organization management, process monitoring and quality assurance.

(1) The topic selection of graduation design (Thesis) should be based on the professional training goal, combined with the technical development and market needs, as well as the practical projects with engineering background and engineering requirements, such as teachers' scientific research, practical engineering, and scientific and technological innovation project of college students, and the subject of professional Scripture design should be retained. The topic of graduation design is to stick to one question per person.

(2)Organization and management in the organization, the establishment of graduation design (paper) guidance institutions, clear guidance procedures, instruct teachers' responsibilities, reflecting the coordination of school and enterprise division of labor. For a real project from a business, business experts usually choose to guide, or school enterprise mentors should cooperate with each other.

(3)Process monitoring from selected topic review, task book examination and approval, issue report, mid-term inspection, to set up a defense group, arrange to review the teacher review, answer, all process monitoring.

(4)It is the key to standardize the process and strengthen the responsibility of the graduation design (paper). It is also the guarantee of the completion and quality of the graduation design (paper). The theoretical basis of graduation design (Thesis) should be sufficient to make the data accurate and the formula deduce correctly; to reflect the theory and practice, and to use the scientific research method, the students should have the ability to analyze and design the practical problems of engineering technology, and do the basic arguments, conclusions and suggestions of the graduation design (Thesis). It has some significance in the application of theory and practice. And the number of words reaches the prescribed range. The drawings, forms and illustrations should be standardized and accurate, and meet the relevant national standards. For graduation design (paper), we should make clear that the index requirements should be less than $30 \%$. 


\section{III. "ENGINEERING ABILITY TRAINING" SYSTEM TAKING THE EXTRACURRICULAR ELECTIVE COURSES AND SCIENTIFIC AND TECHNOLOGICAL ACTIVITIES AS THE CARRIER.}

Interdisciplinary elective courses, reflecting the interdisciplinary and professional integration; science and technology competition has now become an important "engineering ability training" carrier in engineering colleges and universities, which have been paid more and more attention by various colleges and universities.

\section{A. Interdisciplinary elective courses}

The development of Internet not only makes the unrelated industries integrate, it is changing the world, but also changing the engineering education in universities. In the new engineering background, with the impetus of Internet plus, big data, cloud computing, intelligent manufacturing and other hot words and the guidance of national policy, discipline integration is speeding up. In order to meet the needs of industrial development, it is necessary to set up elective courses suitable for the development of social economy and technology to become an inevitable choice for the upgrading of engineering major.

Engineers also need to understand philosophy. Business students can also do engineering experiments, and have gradually become the direction of future higher education reform. To increase professional elective courses is not only to increase the number of elective courses, but also to introduce new technology, improve the quality of professional training, and better adapt to the development of the society.

\section{B. Professional skills competition}

Vocational skills competition is an important means to improve students' practical ability and innovative spirit. It belongs to the ideal carrier of engineering ability training. Encouraging students to participate in various professional competitions and giving credit recognition and rewards is an important way to improve teaching quality, and also the leading role of the second classroom.

In today's rapid development of information technology, combined with network networking + , Chinese intelligent manufacturing 2025, large data and cloud computing background, timely development of skills competition, innovative and entrepreneurial activities can greatly improve the students' learning enthusiasm and engineering application ability.

III. Practice training system for innovation and Entrepreneurship

The construction of innovative and entrepreneurial practice system should be more effective on the basis of the construction of the engineering education community of production research and research cooperation, not only to choose the appropriate training projects in the course, but also to combine the development of the professional technology and the development direction of the country's encouraging industry, so as to choose the hot projects and explore the problems. Training students to solve practical problems.

\section{A. The expansion of intramural courses and experimental projects}

The training of innovation and entrepreneurship in school includes not only the educational content embedded in the innovation and entrepreneurship in the professional curriculum, but also the expansion of the experimental projects in some specialized courses to train the students' innovative and entrepreneurial ability. Some comprehensive experimental projects can be a good training carrier. Through these experimental projects, students have learned the basic solution to the problem. If this is the basis for further expansion of the project, or to solve some technical problems, there is no doubt that the students' ability to solve engineering problems can be greatly promoted. Use. For example, after the electric motor and dragging courses are carried out, the electric specialty can carry out the experiment of variable frequency speed regulation with the current speed regulation mode. If the experimental conditions permit, the vector control experiment of the AC motor can also be carried out.

\section{B. The practice of innovation and entrepreneurship project in school and outside school}

The best thing to do is to combine the specialties of the school. It can be an innovative and entrepreneurial activity at the outside school practice base, including the establishment of an enterprise to conduct business activities. It is mainly to guide the cooperation between the students and the school enterprise, or to undertake some business in a certain way. Through this training, the students can make the students work. Familiarity with the organizational structure, production process, technical services, and the means of operation and the future direction of enterprise development have a good guiding role for the future career development of the students.

Of course, it also includes entrepreneurial practice projects carried out in schools. These projects can be derived from the transformation of research achievements of enterprises or teachers, or the interdisciplinary entrepreneurship projects that combine students and schools. Through the practice of innovation and entrepreneurship, we can improve students' professional quality, scientific research quality and entrepreneurial spirit.

\section{Patent application and transformation of results}

As engineering colleges, technology is the basic condition for survival. Students are more systematically trained in the course of curriculum experiment, curriculum design, comprehensive training, practice and graduation design. Some students will participate in professional skills competition. They will produce some ideas and even inspiration when they have completed the task. Then they should actively guide them to innovate and practice, perhaps. There will be a new type of utility model. Some good ideas or others' achievements can also transform achievements, which is also an effective way to improve students' entrepreneurial ability. 


\section{EVALUATION SYSTEM OF ENGINEERING ABILITY}

In the context of the "new engineering", the engineering education model, to some extent, is not only a teaching reform exploration, but also a practical activity for the students to carry out the full cycle and multidimensional pattern of training [4]. Therefore, a diversified teaching quality evaluation system is essential.

\section{A. Teacher team evaluation}

"New engineering" engineering education not only requires teachers to have profound professional knowledge, rich practical experience, but also have the ability of technological integration. For the current doctorate young teachers, it is very challenging. Therefore, the improvement of teaching staff's ability to teach is a real problem. On the one hand, young teachers should grow up quickly, accumulate teaching experience, and do more engineering projects; on the other hand, the old teachers should also learn new technologies to meet the needs of engineering teaching.

Students' evaluation of teaching is an important work of teaching evaluation. It is the evaluation of teaching effect, which basically embodies the situation of teachers' teaching effect; peer evaluation is the evaluation of teaching level and more objective and just teaching evaluation. Teaching evaluation mainly from teachers' Ideological and moral, business level, teaching content and teaching methods, and other aspects of comprehensive evaluation of the basic quality of teachers, teaching ability and scientific research level. Usually, there are three aspects, including the evaluation of teachers' teaching performance, the evaluation of teachers' teaching quality and the evaluation of teachers' teaching quality by peers.

\section{B. Teacher evaluation}

Teachers' evaluation of students should follow the concept of "new engineering", mainly assess students' thinking, knowledge, ability and personality, etc., which are limited by the requirements of innovative engineering technicians and adopt a variety of evaluation standards.

From the point of view of engineering ability, the emphasis of the experiment is to evaluate the students' ability to combine theory with practice. The curriculum design mainly evaluates the students' knowledge based on the curriculum, the completion of the curriculum design tasks, the evaluation of the ability to use knowledge, and the evaluation of the comprehensive training of professional abilities. The price must be to check the students' ability to apply the knowledge and solve the engineering problems in a comprehensive way. The evaluation of the graduation practice mainly depends on the adaptability of the students and the application ability of the knowledge. The evaluation of the graduation design (paper) focuses on evaluating the students' ability to solve the complex problems, and the emphasis is on the design ideas and technical sides. The evaluation of the law and the completion of the specific content. The evaluation of professional skills competition, scientific and technological achievements and entrepreneurial projects is very intuitive, that is to see the results of the competition, the achievements of scientific and technological achievements and the benefits of the project.

\section{CONCLUSION}

To sum up, in the background of the new engineering, how to build and improve the training system of engineering ability, to do a good job of the cooperative education of production, research and research, and to improve the quality of personnel training in engineering education, is the most important link in the construction of the new engineering education. It is necessary to pay enough attention to it.

The "engineering ability training" system based on the course (or project) as the carrier, the "engineering ability training" system with extracurricular elective courses and scientific and technological activities as the carrier, and the innovation and entrepreneurship practice training system and the evaluation system of engineering ability are the basic construction of the "engineering ability training" system under the new engineering background. The framework needs further research and practice activities to verify and perfect.

\section{ACKNOWLEDGMENT}

First author: Peiyu Li (1963- ), male, Professor of Shandong Jiaotong University, famous teacher in Shandong higher education, research direction: education economy and management, intelligent control technology, rail transportation electric. (Ji'nan, Shandong 250357)

Second author: Wenhui Pei received the B.E. and M.E. degrees in mathematics in 2004 and 2007, respectively, and received the Ph.D. degree in power electronics and power transmission from Shandong University, Jinan, China, in 2012. After graduation, she joined the Shandong Jiaotong University, Jinan, where she is an associate professor with the School of Information and Electric Engineering. Her current research interests include electric vehicles and nonlinear control. (Ji'nan, Shandong 250357).

\section{REFERENCES}

[1] Many colleges and universities put forward the construction of "new engineering" to explore new talents training practice $[\mathrm{N}]$, worker's daily, 2017.5.19.

[2] B Qian, Construction of teaching system of open experiment for engineering based on applied ability training $[\mathrm{J}]$. Experimental Technology \& Management, 2010

[3] Ren Zhenhua and Ceng Xiantao, reform and exploration of civil engineering talents training in Applied Universities under new engineering background $[\mathrm{J}], .2017,3$ of western quality education (17).

[4] MJ Prince, RM Felder,Inductive Teaching and Learning Methods: Definitions, Comparisons, and Research Bases[J]. Research in Higher Education of Engineering, 2006, 95 (2) :123-137. 